\title{
Erratum to: What is Life? Defining Life in the Context of Emergent Complexity
}

\author{
Bruce H. Weber
}

Published online: 27 April 2010

(C) Springer Science+Business Media B.V. 2010

\section{Erratum to: Orig Life Evol Biosph (2010) 40:221-229 \\ DOI 10.1007/s11084-010-9203-4}

The statement in our paper that the replication reaction is "an extreme expression of kinetic control, in which thermodynamic requirements play a supporting rather than a directing role" and the idea that teleonomy derives from that extreme expression of kinetic control, were taken from an earlier publication by Pross (2003) and should have been cited. We apologize for this oversight.

\section{Reference}

Pross A (2003) The driving force for life's emergence: kinetic and thermodynamic considerations. Journal of Theoretical Biology 220:393-406

The online version of the original article can be found under http://dx.doi.org/10.1007/s11084-010-9203-4.

B. H. Weber $(\bowtie)$

Department of Chemistry \& Biochemistry, California State University Fullerton, Fullerton,

CA 92835-6866, USA

e-mail: bhweber@fullerton.edu 